\title{
Divinization, pilgrimage, and social inequality: experiences of women in the access to obstetric assistance
}

Jameson Moreira Belém 1

(iD) https://orcid.org/0000-0003-1903-3446

Emanuelly Vieira Pereira 2

(iD https://orcid.org/0000-0003-1457-6281

Rachel de Sá Barreto Luna Callou Cruz 3

(iD) https://orcid.org/0000-0002-4596-313X

Glauberto da Silva Quirino 4

(iD https://orcid.org/0000-0001-5488-7071

1-4 Programa de Pós-graduação em Enfermagem. Departamento de Enfermagem. Universidade Regional do Cariri. Rua Cel. Antônio Luis, 1161. Bairro Pimenta. Crato, Ceará, Brasil. CEP: 63.105-000. E-mail: jam.ex@hotmail.com

\begin{abstract}
Objectives: to understand the experiences of women from Brazilian northeastern semiarid in accessing obstetric care.

Methods: qualitative research conducted by the methodological framework of ethnonursing, carried out with 13 key informants in a public maternity hospital located in the Cariri region of Ceará in the Brazilian Northeast semiarid. The Observation-Participation-Reflection enablers was adopted for data collection, with observations recorded in a field diary and individual interviews, such as "tell me about". The immersion process in the field lasted five months. The empirical material was submitted to procedures of the data analysis guide for ethno-nursing.

Results: from the patterns that emerged empirically, three cultural themes became evident: "It has to be delivered in the hands of God": discursive constructions about prenatal care; "We stay in this endless coming and going": antepartum pilgrimage; "If I were rich, I wouldn't be here": attention received in accessing maternity.

Conclusions: in the cultural scenario analyzed, women were inserted in the context of clinical and social weaknesses, violation of rights and dignity, resorting to divine designs in the face of difficulties in accessing obstetric services and pilgrimage to guarantee consultations, exams, and hospitalization for childbirth.

Key words Prenatal care, Labor, obstetric, Obstetric nursing, Health services accessibility, Cultural anthropology
\end{abstract}




\section{Introduction}

Women's health should not be seen only from an organic point of view but the complexity of this social phenomenon must be considered, as well as its intersectionality with issues of race/ethnicity, gender, and social class. These dimensions are inserted in the context in which life takes place, and are translated into the conditions in which women live, work, and express the health situation of this social segment, individually and collectively. 1

In the context of reproductive health, interventions carried out within the scope of public services have resulted in improvements of health indicators of Brazilian women. ${ }^{2}$ However, factors such as increased poverty, social inequities, and the disregard of social determinants in the health-disease process influence the exposure to risk factors and vulnerabilities to diseases, conditions, and difficulties in accessing obstetric care services. ${ }^{3}$

Access is defined as the absence of sociocultural, organizational, economic, geographical, and gender barriers in health care; and how the services' capacity to meet the needs of populations at any level of care through adequate infrastructure, human resources, and health technologies. 4

Inequalities related to social class and gender affect women's access to health services and have an impact on the health-disease process, especially among those from less favored social classes and with limited participation in the labor market. 1,5

Due to its territorial extension, the conditions for women's access to obstetric care in Brazil are geographically different, 5,6 varying according to social, demographic and reproductive characteristics, producing significant regional inequalities, especially among indigenous and black women, with less education, a higher number of pregnancies, and residing in the North and Northeast regions of the country. 5

Additionally, the ways of watching and perceiving pregnancy, parturition, and birth are different in different regions of the country as they bring together different perspectives and expectations regarding these events and, consequently, the meanings attributed to the experiences vary according to the socio-cultural scenario. 7

Thus, in adverse individual, social and institutional contexts, women resort to social capital, understood as the set of relationships between people involved in daily life through attitudes and behaviors based on trust, solidarity, cooperation, and reciprocity, as a strategy to face vulnerable and demeaning conditions that give meaning and sense to their health-illness experiences. 1,8

In the public health area, descriptive and qualitative studies attempt to explore the subjective dimension of access to obstetric care services. However, only part of them is anchored in theoretical-methodological references of an anthropological-cultural nature, ${ }^{9}$ reinforcing the need for these approaches to be expanded in research in this area.

Thus, the objective was to understand the experiences of women from the Brazilian Northeast semiarid in accessing obstetric care.

\section{Methods}

This is a qualitative research conducted by the methodological framework of ethno-nursing inserted in the Theory of Universality and Diversity of Cultural Care, suitable for generating a database based on the relationship between care and culture. Ethno-nursing is defined as a process of direct observation, detailed description, documentation, apprehension, and analysis of the ways of life or specific patterns of one or multiple cultures in their naturalistic environments, useful to understand culturally congruent care from an etic and emic perspective. 10

The etic perspective is the external point of view and often the health professionals' view of facts and phenomena. The emic perspective is the internal and native point of view of the individuals and shares with each other for being immersed in cultural patterns. 10

In this study, the emic perspective is approached as the research domain is focused on understanding the meanings that permeate the experiences of women from the semiarid region in accessing obstetric care.

The study was carried out in a public maternity hospital, located in Cariri, Ceará, in the Brazilian northeastern semiarid. It is a reference for the care of women living in six surrounding municipalities, with a total population of 397,246 inhabitants. These municipalities are inserted in a context that historically presents the worst national social indicators, marked by little economic development, a high percentage of poverty, poor housing conditions, becoming the most unequal region in the country. ${ }^{11}$

To understand the research domain from an emic perspective, we intentionally selected 13 key informants in labor and without clinical and/or obstetric complications. Adolescents were excluded because the social, economic, cultural, and historical issues that involve reproductive aspects in this phase are complex and multifactorial.

The field research was carried out from March 
to August 2016. The data was used to collect the Observation-Participation-Reflection trainer, composed of four sequential phases: observation with active listening; observation with limited participation; participation with continued observation; reflection and confirmation of the findings with the informants. 10

In the first phase, observation of the phenomena and active listening obtained an expanded view of the cultural context and documentation in the field diary of the findings. In the second phase, they began to interact gradually through informal conversations. In the third phase, participation became more active and observation decreased. In the last phase, there were reflective observations with a reassessment of information and analysis of the influence exerted on events. 10,12

The observation dynamics included the reception, screening room, nursing station, pre-delivery rooms, relaxation/physiotherapy rooms, delivery, newborn care, and rooming-in, during the morning shifts every day of the week and evening.

The main researcher approached the participants during their admission and hospitalization when he conducted individual "tell me about" interviews focused on women's experiences in accessing obstetric care.

The interviews were recorded on audio, held privately in the admission room and on the obstetric bed during the dilation phase and in the immediate puerperium considering the woman's clinical conditions. They lasted an average of 50 minutes and were finished at the identification of the theoretical data saturation. The content was validated by the participants after transcription.

The empirical material was subjected to the procedures of the data analysis guide for ethnonursing composed of four phases to analyze the information obtained in the field. 10

In phase I, "collection, description, and documentation of raw data", we carried out the organization, coding, and analysis of the information collected to identify contextual meanings and make preliminary interpretations. In phase II, "identification and categorization of components and descriptors", we separated the phenomena by thematic units according to similarities and divergences and the recurring components coded by their meanings. 10

In phase III, "pattern and contextual analysis", we identified the saturation of ideas and recurring patterns containing meanings-in-context. In phase IV, "main themes, research results, theoretical formulations, and recommendations", we abstracted and confirmed the main themes, data synthesis, and interpretation. 10

From the patterns that emerged empirically, three cultural themes became evident: "It has to be delivered in the hands of God": discursive constructions about prenatal care;"We stay in this endless coming and going": antepartum pilgrimage; "If I were rich, I wouldn't be here": attention received in accessing maternity, which was analyzed in an interpretative way.

The six ethno-nursing criteria were adopted to provide methodological rigor and solidity for the results found: credibility, confirmability, recurring standards, meaning-in-context, saturation, and transferability. 10 The study was approved by the Research Ethics Committee under opinion $\mathrm{n}^{\circ} 1.397 .142$ and Certificate of Presentation of Ethical Appreciation $n^{\circ}$ 52703715.0.0000.5055.

\section{Results}

The 13 key informants in the study were between 20 and 41 age group; eight were married; 12 called themselves brown, one was white; all were Christian; eight had completed high school; 11 had paid or unpaid domestic activities and all had family income equal to a minimum wage ( $\mathrm{R} \$ 880.00$ current value at the time). As for gynecologicalobstetric aspects, 11 were multiparous, seven had a gestational age of 40 weeks or more, two reported abortion and the number of prenatal consultations ranged from three to ten.

\section{Cultural themes}

"It has to be delivered in the hands of God": discursive constructions about prenatal care

In this theme, we outlined health needs during pregnancy and the meanings attributed to prenatal care.

The reports showed that the continuity of habitual-risk prenatal care was compromised since most informants did not receive follow-up in Primary Health Care (PHC) due to the shutdown of public services coming from labor strike, referred for follow-up in secondary care in Specialized Medical Assistance Services (SAME - Portuguese acronym): "I hardly had any follow-up with the strike health centers [...], after I completed seven months I didn't go [...] when I arrived the doors were closed"(e5).

In these places, they reported dissatisfaction with the delay, absence of care, and "commitment" of the professionals: "at SAME [...] it was very bad, far from my home, it took too long, I lost all day. Sometimes, there was no doctor or nurse to attend, 
they rescheduled, it was sad. They did not commit; they were too late" (e10).

Given the difficulties in accessing consultations in the PHC, in the service, they were referred and because their health needs were not met, the search for assistance in hospitals became essential: "when I felt something, I came to the hospital, took medicine and it was good [...]. The pressure was high [...] I went to the health center, the woman did not check it [...], I went to the Emergency Care Unit (UPA Portuguese acronym), but nobody checked it, they said it was not a place for pregnant women. They ordered to go to the health clinic, but it was closed"'(e2).

Difficulty in accessing consultations, tests, and medications showed negative feelings throughout pregnancy. These aspects, in addition to the concern of women regarding the health and fetal development, reinforced the imminent need for professional care: "I only had three consultations because I had no medication, ferrous sulfate and I lived far away" (e3); "I am still waiting for my prenatal exams today. This is negligence; you spend the entire pregnancy tense waiting for a result [...]It has to be delivered in the hands of God. These exams we all came to do here at the hospital. I came to have an ultrasound scan now"(e6).

At the PHC, consultations were interspersed between nurses and doctors, although most of the informants performed prenatal care only with nurses, with whom they reported having greater proximity: "when it was the nurse, it was different, she did a lot, measured everything, I listened to the baby's heart, asked a lot of questions, wrote everything about the exams on the card, made us more relaxed"( $(\mathrm{e} 11)$; "The nurse was very good, she assisted me well [...] I did all the monitoring with her" (e8).

On the other hand, the reports showed that medical consultations were faster, superficial, with little dialogue and interaction: "the doctor just looked at the exams and that's it, he didn't measure the belly, he didn't listen to the heart, he didn't pay much attention" (e13); "The doctor was not very good, she was cold" (e12).

"We stay in this endless coming and going": antepartum pilgrimage

In this cultural theme, women recalled the events since the beginning of labor, when they felt the "first pains", which were meant as suffering, and decided to seek assistance. Thus, from these reports, the situations of accessibility of parturient women to maternity were described.

Some women decided to seek care in the first signs and symptoms of labor. However, most reported seeking assistance later: "I started to feel the first pains in the morning, I stayed at home feeling pain all day, I didn't come to the hospital, I said: 'I will only go tomorrow when the pain is strong'. When I realized, I was already losing water [...] The pain was very strong, it only increased, I was in agony [...] I spent the night awake. That was when I decided to come to the hospital, it was very early"(e9).

In the reports, women often complained about difficulties in accessibility to maternity due to the distance from their residence and the lack of conditions and means of transportation to travel. This search for assistance often happened on their own, in cars or motorcycles obtained from people in the community: "we stay in this endless coming and going, they (doctors) think that we do not spend money to pay a person to come and leave here at the hospital. I live in a neighborhood that is a little far away, so I have to get a car"(e5).

In terms of access, maternal experiences were influenced by the comments of people known to the social and community network about the quality of care provided in the maternity hospital or by the woman's experience in previous births: "my friend who came to this hospital said she didn't like it here [...] then I was already scared to come"(e4); "My other daughter took a long time because when I started to feel the pain, I went straight to the hospital. It was the first (son) and I had no understanding since now I started to feel at home and it took me a long time to come to maternity [...] and I was alerted by my colleagues that the service here was slow and that I should only come at the end" (e7).

The support received from members of the social and community network promoted emotional security for women, necessary to face barriers related to access. These women had a voice from someone else and through them, they sought to assure assistance by claiming their rights: "a bad thing to do is when you go and come back. They say: 'come only when the water is broken, bleeding, feeling a lot of pain in the belly'. These five days I came, if you don't know how to talk, keep quiet, don't go after your rights, you come back without being treated like me in the last consultations. This time I brought my friend, I came prepared, that's why they didn't send me back"(e6).

"If I were rich, I wouldn't be here": care received in accessing maternity

In this theme, the parturient women reported 
about the care received in accessing maternity. We show the aspects pointed out by women regarding the care routines that allowed us to understand how the reception was experienced during labor.

Although they reported getting care, the informants pointed out that they had no option regarding the choice of maternity and attributed this to the socioeconomic condition: "we come because there is only this maternity, there is no other. People who are poor and cannot afford to have the baby born are at the mercy of here" $(\mathrm{e} 1)$.

For the informants, "being poor" was a determining condition for the use of public services, which was synonymous with poor quality, precarious care, causing them feelings of (in) conformity: "because of the delay, the assistance was not good. Because people say that the poor complain about everything, of course! [...] If I were rich, I wouldn't be here. And now I'm here, thirsty, hungry. Isn't it negligence for the poor? Poor is the devil's invention! [...] I can't wait for this suffering to end"'(e3).

During the evaluation for admission, women were examined by the obstetrician, resident, and/or medical students. Faced with the diagnosis of labor, they were admitted to the unit to "gain" their child. During this process, there was no nursing reception/screening.

The informants reported long waiting periods, long lines, and the absence of professionals to perform the first appointment: "I arrived at the hospital at about eight o'clock, I went up to the maternity hospital at ten o'clock, [...] because the attendants and the doctor had not arrived. There were six in front of me. And there were still the emergency patients that arrived"(e3). In contrast, those who arrived at the maternity hospital in advanced labor, with clinical and/or obstetric complications, had priority in the evaluation or were immediately admitted.

The difficulties presented in the access, dissatisfaction with the service, fear, and concern about returning home were recurrent among the informants: "The doctor who attended me down there did not want to admit me, he wanted to send me home I did not like him. He should have more attention [...] I was scared, worried about this girl being born [...] I have 40 weeks and two days" (e6).

When not hospitalized, women were instructed by the professionals about the moment to return to the maternity hospital in search of assistance: "He (doctor) said: 'you just come when you feel something', very aggressive! But there are women who have no symptoms, nothing comes out, the water does not break"(e7). These guidelines covered signs and symptoms related to labor such as the presence of bleeding, loss of amniotic fluid and or mucous plug, pain in the lower abdomen, onset, frequency, and intensity of uterine contractions.

The absence of hospitalization was perceived by women as neglect of obstetric care: "'Only come back when you feel something', I think this is absurd! It seems that there is a doctor who does not like having a cesarean" (e6). When they managed to overcome this barrier, they attributed this achievement to divine intercession, emphasized in "things are everything as God wants, He touched the heart of this doctor" (e7).

Some women did not understand or accept without questioning medical conduct: "we cannot even complain, because I am afraid they will send me home" (e3); "I was bleeding, the doctor examined the child's heartbeat, and said it was normal, did the touch (vaginal) and said I had a fingerprint, something like that, I didn't understand, he spoke Greek to me" ( e5).

Professional behavior was referred to as satisfactory when women were admitted quickly and or were in advanced labor. This aspect reflected a supposed resolution as it ensured immediate hospitalization: "it didn't take long. I arrived and had the baby.I did not have much suffering. Here a nurse helped me and in an instant, she was born. The water broke and they sent me to the delivery room, there was no cut, there was no stitch" (e10).

\section{Discussion}

Qualified access to obstetric care is a challenge, especially in regions with difficulties in organizing the health care network. In the cultural context analyzed, obstetric care was highlighted by difficulties in access, accessibility, and violation of rights at different levels of care.

These aspects resulted in low attendance to prenatal care, pilgrimage to health services and the absence of a minimum standard of care. The Ministry of Health's recommendation covers carrying out at least six consultations, starting in the first quarter, procedures, clinical-obstetric, laboratory tests, and guidelines aimed at health promotion. 13

In this complex scenario, informants without financial conditions moved by concern sought ways and resources to perform obstetric exams or resorted to divine designs as a way to alleviate suffering and or coping mechanism. Due to the insecurity that permeates pregnancy and childbirth, women tend to cling to religious aspects to receive divine protec- 
tion. 14

The (in) conformation emphasized in "It has to be delivered in the hands of God" may denote at first, ignorance and or passivity for the claim of rights, but essentially reinforces the inequality of access to services and neglected rights. It is noteworthy that in poor regions about $60 \%$ of pregnant women do not have access to a minimum standard of clinical and laboratory care. ${ }^{7}$

The absence of links to reference maternity hospitals or diagnostic services and the centralization of prenatal care in secondary care services determined pilgrimage. In order to avoid displacement of the registered area, 15 during the organization of prenatal care, individual, socioeconomic and cultural characteristics, the availability, spatial distribution and proximity of health services to the community should be considered, 16 as well as guidance on how to search for referral services when presenting signs and symptoms of labor, clinical or obstetric complications. 16

These aspects, when not considered, contribute to the fragmentation of prenatal care by reinforcing the hospital-centered logic as pregnant women do not have their health needs met. In health itineraries, personal trajectories become central to this logic when situations of vulnerability and violations of rights are observed in the social process associated with distances and barriers in accessing PHC services. ${ }^{17,18}$

Prenatal consultations were interspersed between doctors and nurses, as recommended by the Ministry of Health. However, this service dynamic still faces consolidation difficulties. In the South, Southeast, and Midwest regions of Brazil, prenatal consultations are performed predominantly by doctors, however, in the North and Northeast, half of the prenatal consultations are performed by nurses. 16

The spaces for listening and dialogue established with the nurse, translated in the opening to express doubts and concerns are a positive evaluation of the service by generating feelings of trust and security. However, the actions described turned to standardized routine aspects, by emphasizing procedures and technical actions performed in the consultation.

Nursing care in prenatal care needs to go beyond the biological, technical, and problem-centered dimensions and value aspects of the socio-cultural context, subjective and affective dimensions of women, to guarantee comprehensive care and culturally congruent care. 18

Medical consultations anchored in a reductionist logic were limited to technical procedures and exam evaluation. These aspects refer to the influence of the biomedical model on professional practices 19 that consequently result in weakness in the evaluation and satisfaction of assistance by women who have grasped a logic of health care restricted to the physical scope.

Thus, overcoming this standardization and generalization of care actions is to consider that there is no single form of care that can be scripted and universally prescribed, nor seen as an object that can be legitimized and reproduced as there are distinct health needs to be socioculturally contextualized.

The late search for childbirth assistance is associated with finding a place in a hospital, assisted without delay, the speed of birth, previous experiences, and the result of the comparison between care received and the report of other women. The satisfaction of women is associated with the punctual performance of some health professionals, the speed of labor and birth, little pain, and absence of complications. 20

During the antepartum pilgrimage, most women sought assistance by their means. The implementation of a transport system, with transfers of pregnant women at risk or in labor, carried out by ambulances, would provide shelter to the parturient women and reduce potential risks during the journey and inequalities. ${ }^{21}$

Community members (neighbors, friends, colleagues, and godmothers), as elements of social capital inserted in the formal and informal social and community networks of women, provide support to women, helping to alleviate "suffering" and limited autonomy and empowerment during the parturition process. 1,22

Thus, it is evident that from the perspective of health promotion, empowerment and discursive change based on the claim of rights based on legal mechanisms (Federal Law n ${ }^{\circ} 11.108 / 2005$ ), assistance (rules and recommendations of Rede Cegonha - Stork Network) and educational activities are elements present in the social capital that are decisive to break barriers of access to health services. 1,22

The presence of a companion of the woman's choice, part of her social and community network conveys confidence, physical and emotional support. 23 In addition, the implantation of reception with risk classification constitutes the institutional voice of women when configuring the organization strategy of the work process in health, ensuring efficient, equitable, and comprehensive care. 24

The type of delivery and the ideas built around parturition have a socioeconomic profile. The expectations of middle-class women are marked by 
empowerment and autonomy, a lower level of assistive technology interventions, greater participation, and control over the process. On the other hand, the poor are inserted in contexts of vulnerability and heteronomy as they try to shorten the situation of pain and suffering through professional interventions. 20

The resignation present in the informants discourse reflected in the condition of submitting to the action of destiny and peacefully accepting the sufferings of life is permeated by a feeling of helplessness that reflects a place of speech that goes beyond what could be classified as subjective poverty, "coming of the people from their context and history", 8 but as a poignant reflection of how socioeconomic inequalities afflict and imprison people in a perverse routine.

Social inequalities and the decrease in financial investment in recent years are added within the scope of the Unified Health System (SUS), which compromises the ability to meet the demand from the perspective of universality and comprehensiveness, 25 the absence of its appropriation as a right and representations anchored in negative views of the system among the middle class. 26

There is a shared perspective among the informants that maternity wards are safe places for childbirth. The routines of modern hospital obstetrics build the narrative that motherhood is a place endowed with professionals and assistive technologies that give women the capacity, protection, and conditions necessary for parturition and essential to maternal-fetal well-being. 27

The place of power resulting from medical knowledge and the lack of translation of knowledge that would allow women to understand what is being done and said is based on hegemonic, hierarchical, and asymmetric relations of knowledge and power. In the maternity space, there is the legitimation of these relationships, control over bodies, and centralization of decision-making processes in the figure of the doctor who, through his technical-scientific training, takes charge of the actions and leads to parturition. 28 This phenomenon is aggravated by the lack of adequate information for women during prenatal care on aspects related to labor and their rights.

In terms of reflexivity, the use of ethno-nursing in the cultural context analyzed presents a look at the perspectives of obstetric care as it considers the health needs of the participants from the perspective of their cultural group and reveals the humanistic and subjective dimensions present in their daily lives that need to be understood and incorporated into assistance to promote culturally congruent care practices.

\section{Final considerations}

In the cultural scenario analyzed, the informants' experiences in accessing obstetric care were woven amid contexts of clinical and social weaknesses, violation of rights, and dignity. Women resorted to divine designs to intercede the obstacles faced in accessing health services, difficulties in socio-organizational and geographic accessibility, and pilgrimages to guarantee the right to prenatal consultations, exams, and hospitalization for childbirth. This context, attributed by the participants to social inequality, resulted in feelings of resignation and disability in the face of the helplessness that afflicted them.

Leading the professionals responsible for obstetric care to include in their actions, social, cultural, and subjective aspects for the provision of culturally congruent care and the governmental bodies guarantee the universality of access to services and public health policies in Brazil through equal, fair and dignified opportunities based on integrality, equity, and quality of services, considering social (class, race/ethnicity, gender) and cultural markers, resistant patterns of socio-spatial inequalities and areas of vulnerability in certain regions of the country are challenges to be taken on.

\section{Acknowledgments}

To Fundação Cearense de Apoio ao Desenvolvimento Científico e Tecnológico (FUNCAP) for financial support. Awarding of Master's Scholarships.

\section{Authors' contribution}

Study design: Belém JM, Quirino GS; Data collection: Belém JM; Analysis and interpretation of data: Belém JM, Quirino GS, Pereira EV, Cruz RSBLC. All authors approved the final version of the article. 


\section{References}

1. Geib, LTC. Social determinants of health in the elderly. Ciênc Saúde Coletiva. 2012;17(1):123-33.

2. Leal MC, Szwarcwald CL, Almeida PVB, Aquino EML, Barreto ML, Barros F, Victora C. Reproductive, maternal, neonatal and child health in the 30 years since the creation of the Unified Health System (SUS). Cien Saúde Coletiva. 2018; 23(6):1915-28.

3. Fiorati RC, Arcêncio RA, Souza LB. Social inequalities and access to health: challenges for society and the nursing field. Rev Latinoam Enferm. 2016;24:e2687.

4. Pan American Health Organization. Strategy for universal access to health and universal health coverage. Proceedings of the 53rd Directing Council (CD53/5, Rev. 2) [Internet]. 2014 [acesso 2019 Out 20]. Disponível em: https://www.paho.org/hq/dmdocuments/2014/CD53-5-e.pdf

5. Domingues RMSM, Viellas EF, Dias MAB, Torres JA Theme-Filha MM, Gama SGN, Leal MC. Adequação da assistência pré-natal segundo as características maternas no Brasil. Rev Panam Salud Pública. 2015;37(3):140-7.

6. Guimarães WSG, Parente RCP, Guimarães TLF, Garnelo L. Access to prenatal care and quality of care in the Family Health Strategy: infrastructure, care, and management. Cad Saúde Pública. 2018; 34(5):e00110417.

7. Tostes NA, Seidl EMF. Expectativas de Gestantes sobre o Parto e suas Percepções acerca da Preparação para o Parto. Temas Psicol.(online). 2016; 24(2):681-93.

8. Freitas MA, Mattos ATR; Gomes WZ, Caccia-Bava MCGG Who are they, what do they talk about and who listens to the poor?. Ciênc Saúde Coletiva. 2017;22(12):3859-82.

9. Aredes JS, Firmo JOA, Leibing A, Giacomin KC. Reflexões sobre um fazer etnográfico no pronto-socorro. Cad Saúde Pública. 2017; 33 (9): e00118016.

10. Leininger MM, McFarland MR. Culture care diversity and universality: a worldwide nursing theory. Sudbury, MA: Jones \& Bartlett Learning; 2 ed.; 2006.

11. Hissa-Teixeira K. Uma análise da estrutura espacial dos indicadores socioeconômicos do nordeste brasileiro (20002010). Eure. 2018; 44 (131):101-124.

12. Silveira RS; Martins CR, Lunardi VL, Lunardi Filho WD Etnoenfermagem como metodologia de pesquisa para a congruência do cuidado. Rev Bras Enferm. 2009; 62 (3): 442-6.

13. Nunes JT, Gomes KRO, Rodrigues, MTP, Mascarenhas MDM. Qualidade da assistência pré-natal no Brasil: revisão de artigos publicados de 2005 a 2015. Cad Saúde Coletiva. 2016; 24 (2): 252-61

14. Bezerra MGA, Cardoso MVLML. Fatores culturais que interferem nas experiências das mulheres durante o trabalho de parto e parto. Rev Latinoam Enferm. 2006; 14 (3): 41421.

Received on June 2, 2020

Final version presented on December 19, 2020

Approved on January 5, 2021
15. Cabral FB, Hirt LM, Sand ICPVD. Prenatal care from puerperal women's point of view: from medicalization to the fragmentation of care. Rev Esc Enferm USP. 2013; 47 (2): 281-7.

16. Viellas EF, Domingues RMSM, Dias MAB, Gama SGN, Theme Filha MM, Costa JV, Bastos MH, Leal MC. Prenatal care in Brazil. Cad Saúde Pública. 2014; 30 (supl. 1): 85100.

17. Maffacciolli R, Oliveira DLLC, Brand EM. Vulnerabilidade e direitos humanos na compreensão de trajetórias de internação por tuberculose. Saúde Soc. 2017; 26 (1): 286-99.

18. Alves CN, Wilhelm LA, Barreto CN, Santos CC, Meincke SM, Ressel LB. Prenatal care and culture: an interface in nursing practice. Esc Anna Nery Rev Enferm. 2015; 19 (2): 265-71

19. Warmling CM, Fajardo AP, Meyer DE, Bedos C. Social practices in the medicalization and humanization of prenatal care. Cad Saúde Pública. 2018; 34 (4): e00009917.

20. Dias MAB, Deslandes SF. Expectativas sobre a assistência ao parto de mulheres usuárias de uma maternidade pública do Rio de Janeiro, Brasil: os desafios de uma política pública de humanização da assistência. Cad Saúde Pública. 2006; 22 (12): 2647-55.

21. Menezes DCS, Leite IC, Schramm JMA, Leal MC. Avaliação da peregrinação anteparto numa amostra de puérperas no Município do Rio de Janeiro, Brasil, 1999/2001. Cad Saúde Pública. 2006; 22 (3): 553-9.

22. Marrero L, Brüggemann OM, Costa R, Junges CF, Scheneck CA. Institutional violence reported by birth companions in public maternity hospitals. Acta Paul Enferm. 2020; 33: eAPE20190220

23. Brüggemann OM, Oliveira ME, Martins HEL, Gayeski ME. The integration of the birth companion in the public health services in Santa Catarina, Brazil. Esc Anna Nery Rev Enferm. 2013; 17 (3): 432-38.

24. Sousa TS, Andrade MU, Almeida MS, Nunes IM, Carvalho MM. Acolhimento com classificação de risco: a voz das mulheres. Rev Baiana Enferm. 2013; 27 (3): 212-20.

25. Teixeira CFS, Paim JS. A crise mundial de 2008 e o golpe do capital na política de saúde no Brasil. Saúde Debate. 2018; 42 (2): 11-21.

26. Reigada CLL, Romano VF. O uso do SUS como estigma: a visão de uma classe média. Physis (Rio J.). 2018; 28 (3):e280316.

27. Gonçalves R, Aguiar CA, Merighi MAB, Jesus MCP. Experiencing care in the birthing center context: the users' perspective. Rev Esc Enferm. USP. 2011; 45 (1): 62-70.

28. Pereira RR, Franco SC, Baldin N. Representações sociais e decisões das gestantes sobre a parturição: protagonismo das mulheres. Saúde Soc. 2011; 20 (3): 579-89. 